\title{
Pharmacologic Treatment of Meningitis and Encephalitis in Adult Patients
}

\author{
Andrew K. Treister ${ }^{1} \quad$ Ines P. Koerner ${ }^{2}$ \\ ${ }^{1}$ Department of Neurology, Oregon Health \& Science University, \\ Portland, Oregon, United States \\ 2Department of Anesthesiology and Perioperative Medicine, \\ Oregon Health \& Science University, Portland, Oregon, \\ United States
}

\begin{abstract}
Address for correspondence Andrew K. Treister, MD, Department of Neurology, Oregon Health \& Science University, 3181 SW Sam Jackson Park, CR 120, Portland, OR 97239-3098, United States (e-mail: treistea@ohsu.edu).
\end{abstract}

\begin{abstract}
Keywords

- meningitis

- encephalitis

- antibiotic resistance

Meningitis and encephalitis are two inflammatory, often infectious, disorders of the meninges and the central nervous system. Both are associated with significant morbidity and mortality, and require early and aggressive targeted treatment. This article reviews pharmacologic treatment strategies for infectious meningitis and encephalitis, using the latest available research and guidelines. It provides an overview of empiric antimicrobial treatment approaches for a variety of organisms, including a discussion of trends in antibiotic resistance where applicable. Key steps in diagnosis and general management are briefly reviewed.
\end{abstract}

\section{Introduction}

The terms meningitis and encephalitis comprise a broad array of infectious and inflammatory processes involving the central nervous system (CNS) that carry significant morbidity and mortality. ${ }^{1,2}$ Meningitis refers to inflammation of primarily the meninges, although it may spread to involve the nearby cortex, cranial nerves, and vasculature. Encephalitis, in contrast, is usually reserved to describe inflammation that originates in the brain parenchyma. Though encephalitis is commonly associated with viral infection or autoimmune or paraneoplastic processes, bacterial and other nonviral infections of the brain parenchyma are often referred to as cerebritis. Meningitis and encephalitis can be caused by bacteria, viruses, fungi, and other microorganisms. Autoimmune conditions are becoming increasingly recognized as an important mimic of infectious causes of CNS inflammation, especially encephalitis. Both infectious and noninfectious inflammation of the CNS can result in longterm complications, such as epilepsy, hydrocephalus, static encephalopathy, and death, and thus warrant early and aggressive intervention. ${ }^{3}$

This review provides an overview of the most common causes of treatable meningitis and encephalitis with emphasis on current widely accepted pharmacologic treatment protocols. Additionally, it discusses practical approaches to rising trends of antibiotic resistance where appropriate. Health care-associated infections are not covered in detail, as they are excellently discussed in a recent guideline statement. ${ }^{4}$

\section{Literature Review}

PubMed was searched in January 2019 for articles published between January 1, 2009, and December 31, 2018. Initial searches were for "meningitis" and "encephalitis" together with "treatment" and "therapy." After screening abstracts, the most recent and authoritative articles focusing broadly on community-acquired meningitis and encephalitis were reviewed in depth and used to outline the article. Original research articles are referenced when available to support the compiled recommendations. Guidelines from governmental bodies and academic societies were utilized when more current literature-based recommendations were not available. Studies referenced in relevant articles were included, as were older references known to the authors.

\section{General Recommendations}

As infectious meningitis and encephalitis are potentially lethal, targeted antimicrobial treatment should be initiated as early as possible, ideally within the first hour of patient presentation. A delay of only 3 hours in treatment of bacterial meningitis has been associated with a significantly increased risk of mortality. ${ }^{5}$ Lumbar puncture and cerebral spinal fluid (CSF)

\section{received}

February 5, 2019

accepted after revision

May 19, 2019
DOI https://doi.org/

$10.1055 / \mathrm{s}-0039-1692868$

ISSN 2348-0548.
Copyright $\odot 2019$ Indian Society of Neuroanaesthesiology and Critical Care
License terms

(1) (1) $\Theta \circledast$ 
analysis and culture can provide critical diagnostic information and guide antimicrobial choices. Empiric therapy should not be delayed if lumbar puncture is delayed or contraindicated, for example in patients who present with coagulopathy or with space-occupying brain lesions that put them at risk of herniation if spinal fluid is removed from the lumbar space. Blood cultures should be obtained from all patients, as bacterial meningitis is often associated with bacteremia.

\section{Infectious Meningitis and Encephalitis}

\section{Bacterial Meningitis}

Bacterial meningitis primarily involves the meninges but can cause a profound inflammatory response in the local brain and spinal cord tissue. The classic presentation, a triad of fever, nuchal rigidity, and rapidly progressing change in the mental status, is present in less than one-half of patients presenting with community-acquired meningitis. ${ }^{2}$ Headache is common. Other manifestations such as seizures (viral encephalitis), focal neurologic deficits (due to abscess or edema), rash (especially seen with Neisseria meningitidis), and nausea are present in many patients. ${ }^{6}$

When bacterial meningitis is suspected, workup should be expedited and empiric antibiotics must be started as quickly as possible. In resource-rich settings where computed tomography $(\mathrm{CT})$ of the head is readily available, obtaining a CT scan prior to lumbar puncture may reduce the risk of herniation in those with space-occupying lesions. This may be most useful in patients who present with moderate or severe encephalopathy or focal neurologic deficits. ${ }^{6}$ CT imaging should not delay lumbar puncture or initiation of empiric antimicrobial therapy. Similarly, antibiotics should not be delayed while cultures are pending. CSF pleocytosis or elevated white cell count $>1,000 / \mathrm{mL}$ has very high specificity for bacterial meningitis. ${ }^{7}$ However, a bacterial cause of meningitis cannot be excluded when CSF white cell counts are elevated to a lesser degree. Similarly, low CSF glucose, reduced CSF/blood glucose ratio, and elevated CSF protein levels are suggestive of bacterial meningitis, but it can also be seen in viral meningitis or with systemic infections. ${ }^{7}$ In florid meningitis, bacteria may be identified on CSF Gram stain, which helps target appropriate antibiotic choices. As current laboratory parameters are insufficiently specific to differentiate viral and bacterial meningitis, much interest is focused on developing alternative diagnostic methods. CSF lactate as well as CSF and serum procalcitonin levels both hold promise as additional tools to aid in the differentiation between bacterial and viral meningitis, although sensitivity and specificity vary widely between studies. ${ }^{8-10}$

While a lumbar puncture is most likely to accurately identify the causative organism if performed prior to antibiotic administration, delivering antibiotics should not be delayed for the procedure. Even though the ability to culture bacteria from the CSF drops after administration of antibiotics, the sample will often still show a CSF profile consistent with bacterial meningitis (neutrophilic pleocytosis with high white cell count, low glucose, elevated protein, and elevated opening pressure), thus assisting in diagnosis. When available, polymerase chain reaction (PCR) offers a much more sensitive approach to identifying microbes in CSF than traditional culture, although specificity may be reduced. ${ }^{11}$ Large-scale studies comparing PCR and culture are lacking.

\section{Epidemiology and Empiric Antimicrobial Regimen}

Bacterial meningitis is most prevalent in sub-Saharan Africa, where incidence reaches 1,000 cases per 100,000 people per year, compared with 1 to 2 cases per 100,000 in Europe and the United States. Incidence of the "big three" bacterial sources with highest prevalence worldwide, Streptococcus pneumoniae, N. meningitidis, and Haemophilus influenzae, has dropped significantly in the past decades, mostly secondary to effective childhood vaccines that have become widely available and continue to protect into adulthood. ${ }^{11,12}$

Several empiric treatment regimens have been established based on a given patient's age to cover the most likely responsible bacterium. In adults under the age of 50 years, empiric treatment should include vancomycin and a third-generation cephalosporin to cover the most common organisms S. pneumoniae and $N$. meningitidis and to account for possible penicillin resistance. ${ }^{13}$ In patients older than 50 years, Listeria monocytogenes must also be considered, and therefore ampicillin should be added to the other two agents. ${ }^{13}$ In immunocompromised patients and those at risk for nosocomial infection after invasive procedures or complicated head trauma, Staphylococcus aureus and Pseudomonas aeruginosa should also be considered, and should be targeted with vancomycin along with a fourth-generation cephalosporin or meropenem. ${ }^{13}$ We provide specific treatment recommendations targeting different microbial sources in the text below and summarize them in - Table 1. While we have taken every effort to ensure these recommendations are up to date, we cannot accept responsibility for errors. We advise the reader to use common sense when choosing treatments, and to also refer to local practices and recommendations. All empiric antibiotic regimens should be appropriately narrowed when culture data are available.

While empiric therapies are keys to an emergency department or inpatient physician's arsenal and are lifesaving for patients with bacterial meningitis, frequent inappropriate use of antibiotics globally has contributed to widespread patterns of resistance that may threaten the empiric use of cephalosporins. A recent study from India demonstrated an increase in cefotaxime resistance in isolates from pneumococcal meningitis cases from $<5 \%$ in 2008 to $>25 \%$ in 2016. ${ }^{14}$ With this in mind, it is important for practitioners to be cognizant of their regional resistance patterns in concert with broader treatment recommendations.

\section{Community-Acquired Meningitis Streptococcus pneumoniae}

$S$. pneumoniae is the most common cause of bacterial meningitis in adults. In a recent U.S. study of 1,083 patients, it was found to be the cause of $71 \%$ of cases..$^{15}$ Mortality is high (up to $19-37 \%$ ), with up to $30 \%$ of survivors affected by residual hearing loss and other neurologic sequelae. ${ }^{16}$ 
Table 1 Common causes of bacterial meningitis and first-line treatment

\begin{tabular}{|c|c|c|}
\hline Organism & Clinical considerations & First-line treatment \\
\hline $\begin{array}{l}\text { Streptococcus } \\
\text { pneumoniae }\end{array}$ & Most common bacterial pathogen in adults & $\begin{array}{l}\text { Vancomycin, ceftriaxone; consider } \\
\text { dexamethasone }^{a}\end{array}$ \\
\hline Listeria monocytogenes & $\begin{array}{l}\text { Unpasteurized dairy products, neonates and elderly } \\
\text { patients }\end{array}$ & Ampicillin \\
\hline Neisseria meningitidis & $\begin{array}{l}\text { Children and young adults, petechial rash, local and } \\
\text { regional outbreaks }\end{array}$ & Ceftriaxone \\
\hline Haemophilus influenzae & $\begin{array}{l}\text { Children (especially unvaccinated); immunocompro- } \\
\text { mised adults }\end{array}$ & Ceftriaxone \\
\hline $\begin{array}{l}\text { Mycobacterium } \\
\text { tuberculosis }\end{array}$ & Immunosuppressed patients & $\begin{array}{l}\text { Isoniazid, rifampin, ethambutol, } \\
\text { pyrazinamide }\end{array}$ \\
\hline Gram-negative bacilli & $\begin{array}{l}\text { Nosocomial infections; patients after neurosurgical } \\
\text { procedure }\end{array}$ & Third and fourth-generation cephalosporins \\
\hline Staphylococcus species & $\begin{array}{l}\text { Nosocomial infections; neurosurgical or trauma } \\
\text { patients }\end{array}$ & Vancomycin with other empiric treatment \\
\hline
\end{tabular}

Fortunately, with the recent advent of vaccines, the incidence of infection of invasive species of $S$. pneumoniae has decreased by almost one-half; from 24 to 14 cases per $100,000 .{ }^{17}$

Though historically treated with high-dose penicillin, ubiquitous penicillin-resistant strains require third-generation cephalosporins as the cornerstone of empiric first-line treatment. ${ }^{18}$ As cephalosporin-resistance emerges at increasing rates, vancomycin, a powerful agent against gram-positive species, although with inconsistent blood-brain barrier penetrance, is widely used as an adjunct. ${ }^{13}$ An initial empiric regimen to cover $S$. pneumoniae meningitis includes:

- Vancomycin (15-20 mg/kg IV every 8-12 hours)

- Ceftriaxone (2 g IV every 12 hours) or cefotaxime (2 g IV every 4-6 hours)

Dexamethasone has been studied as an adjunct to antibiotic treatment in bacterial meningitis, to blunt the inflammatory response to rapid bacterial lysis. Studies on the benefit of dexamethasone to improve survival and reduce neurologic complications of meningitis found divergent effects in resource-rich and resource-poor countries. A Cochrane review from 2015 showed a significant reduction in hearing loss and neurologic sequelae following bacterial meningitis in resource-rich countries only. ${ }^{19}$ This may relate to differences in incidence of $S$. pneumoniae meningitis, as dexamethasone appears most effective when $S$. pneumoniae is the infectious agent. A suggested dosing regimen is $0.15 \mathrm{mg} / \mathrm{kg}$ dexamethasone every 6 hours for four days). ${ }^{18}$ Providing dexamethasone after antibiotics have been initiated appears less helpful.

In patients with a known severe allergy to either cephalosporins or vancomycin, moxifloxacin can be considered for use in place of the problematic first-line agent based on prior in vitro studies, ${ }^{20,21}$ though prospective trials are lacking.

\section{Neisseria meningitidis}

$N$. meningitidis meningitis is a common cause of community-acquired meningitis, classically in children and young adults. ${ }^{22}$ In contrast to other organisms, the classic triad of bacterial meningitis is less common, but the addition of a petechial rash to other meningitic symptoms is more helpful in clinical diagnosis. ${ }^{22}$ One study of 258 patients measured mortality in $7 \%$ of patients, moderate to severe disability in $4 \%$, and favorable outcome in $88 \%{ }^{22}$ The most common neurologic sequela was hearing loss. ${ }^{22}$

$N$. meningitidis is often susceptible to penicillin G, though due to rising resistance rates, third-generation cephalosporins are the initial treatment of choice. ${ }^{13}$ Ceftriaxone is the preferred initial treatment, and if susceptibility testing is available and demonstrates a lack of penicillin resistance, the patient may be switched to penicillin G 300,000 U/kg/day for the rest of the treatment duration. ${ }^{13,18}$

$N$. meningitidis is frequently associated with regional outbreaks, especially in sub-Saharan Africa, and in times of epidemic in centers with limited resources, single doses of long-acting chloramphenicol ( $100 \mathrm{mg} / \mathrm{kg}$ to a maximum of $3 \mathrm{~g}$ ) or ceftriaxone (100 mg/kg to a maximum of $4 \mathrm{~g}$ ) can be used. ${ }^{23}$

\section{Listeria monocytogenes}

L. monocytogenes is a gram-positive rod found in unpasteurized dairy products that epidemiologically strikes in a bimodal distribution, affecting neonates and elderly patients. ${ }^{3}$ Ampicillin (2 g IV every 4 hours) is the preferred first-line agent, though in confirmed cases, many opt to add gentamicin ( $5 \mathrm{mg} / \mathrm{kg} /$ day divided into three doses per day) for its synergistic effects. ${ }^{24}$

\section{Haemophilus influenzae}

$H$. influenzae type B was classically known as a common cause of pediatric meningitis, but is scarcely seen in developed countries since the advent of the $H$. influenzae vaccine. ${ }^{25}$ With rising rates of resistance to ampicillin, ceftriaxone or cefotaxime is the preferred agent. ${ }^{13}$

\section{Mycobacterium tuberculosis}

Tuberculosis can affect the CNS in multiple patterns, including meningitis, tuberculomas, abscesses, and radiculomyelitis. ${ }^{26}$ Those at risk for CNS manifestations of tuberculosis include patients with malnutrition, alcoholism, human 
immunodeficiency virus (HIV), malignancy, other immune dysfunction, and history of measles. ${ }^{26}$ Treatment as per the World Health Organization (WHO) guidelines is the same as for pulmonary tuberculosis with the following combination of antimicrobial agents ${ }^{26,27}$ :

- Isoniazid (10 mg/kg/day orally with $50-100 \mathrm{mg}$ pyridoxine daily)

- Rifampin (15 mg/kg/day orally)

- Ethambutol (15 mg/kg/day orally)

- Pyrazinamide (30-35 mg/kg/day orally)

Patients should be treated with the four-drug regimen for 2 months, followed by 10 months of rifampin and isoniazid.

Resistance to antituberculosis agents is widespread, and though the patient may have been primarily infected with a resistant organism, resistance is more frequently seen as a later complication of medication nonadherence or partial adherence. ${ }^{28}$ While there have been no randomized controlled trials for treatment of multidrug-resistant CNS tuberculosis, an alternative regimen that can be considered after treatment failure or detection of a resistant strain includes levofloxacin, kanamycin, ethionamide, linezolid, and pyrazinamide. $^{29}$

\section{Neuroborreliosis}

Lyme disease is a systemic illness caused by the Ixodes tickborne spirochetes Borrelia burgdorferi, Borrelia garinii, and Borrelia afzelii. ${ }^{30}$ The systemic syndrome is often heralded by the classic erythema migrans or targetoid rash $(\boldsymbol{- F i g .} \mathbf{1})$ at

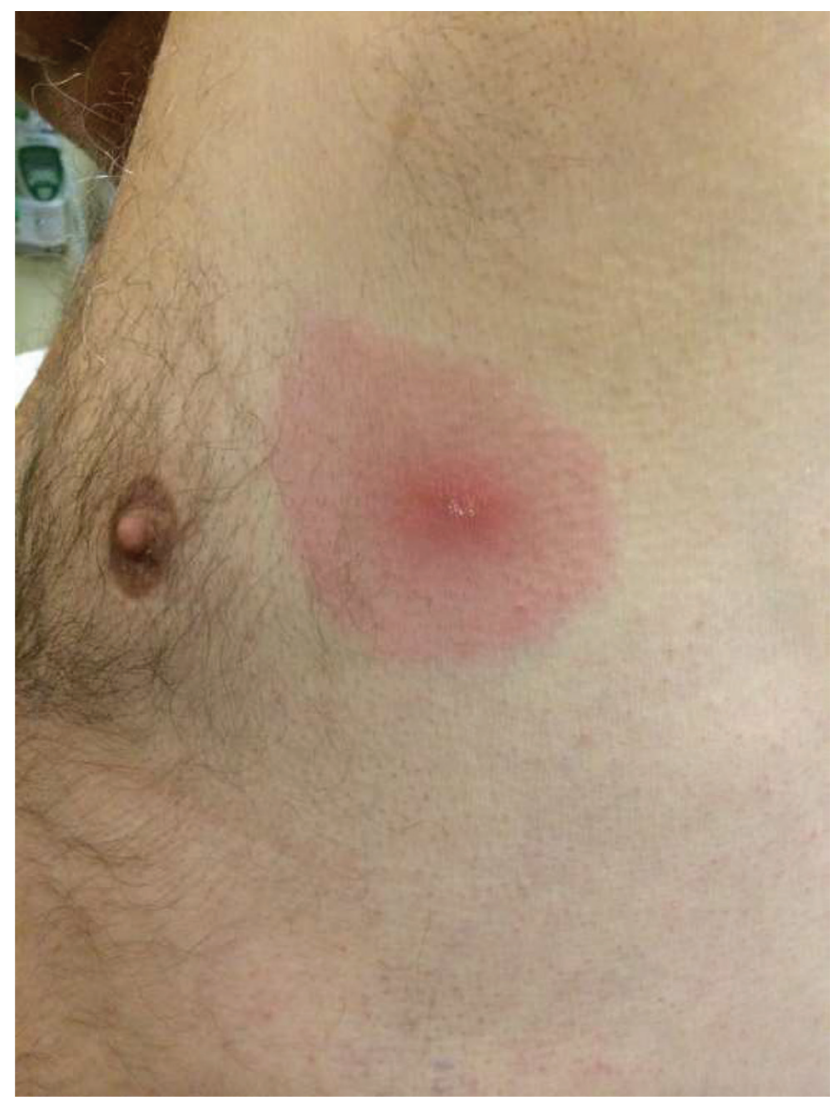

Fig. 1 Targetoid rash or erythema migrans, seen in early cutaneous Lyme disease. the site of the tick bite and often accompanied later by severe radicular and joint pains. ${ }^{30}$ The neurologic manifestations affect 10 to $15 \%$ of those who are not adequately treated and can include meningitis, radiculitis, cranial neuritis (most often affecting the facial nerve), peripheral neuropathy, and rarely, encephalomyelitis. ${ }^{30}$

Fortunately, neuroborreliosis is known to be quite responsive to first-line therapy. Doxycycline $(100 \mathrm{mg}$ orally twice daily for 2-4 weeks) was shown to be as effective in treating most forms of neuroborreliosis as parenteral ceftriaxone ( $2 \mathrm{~g} /$ day for 2-3 weeks). ${ }^{31}$ However, formal trials regarding the treatment of Lyme-related encephalomyelitis are lacking, and the acuity of the patient's illness should be taken into consideration when determining the best route for administration.

\section{Neurosyphilis}

As with Lyme disease, the neurologic manifestations of infection by the spirochete Treponema pallidum usually arise much later than the initial cutaneous lesions. A clinical meningitis, uveitis, or retinitis can occur in the secondary phase of untreated syphilis. ${ }^{30}$ Late or tertiary neurosyphilis is rarer and can present in a variety of ways, including strokes from meningovascular involvement, meningoencephalitis, posterior column and radicular disease ("tabes dorsalis"), parenchymatous mass lesions ("gummas"), and dementia ("general paresis"). ${ }^{30}$

Penicillin $G$ remains the mainstay of treatment for all forms of syphilis, and neurosyphilis should be treated with 3 to 4 million units of penicillin G every 3 to 4 hours for 10 to 14 days. ${ }^{32}$

\section{Nosocomial Meningitis}

\section{Gram-Negative Bacilli}

Gram-negative bacilli rarely cause community-acquired bacterial meningitis in adults. They are far more likely to be encountered as nosocomial pathogens in patients after invasive neurosurgical procedure or complicated head trauma. Given the ever-expanding resistance patterns, treatment is dependent on identifying the organism and its susceptibilities. Common pathogens include Klebsiella species, Pseudomonas species, Acinetobacter baumannii, and Escherichia coli. ${ }^{33,34}$ Third- and fourth-generation cephalosporins are common first-line empiric agents, though carbapenems can be considered as well. ${ }^{13}$ Resistant organisms may require the use of aminoglycosides, polymyxin $\mathrm{B}$, or colistin via intravenous or intrathecal route. ${ }^{13,34,35}$

The use of intrathecal or intraventricular antibiotics is an important option to consider as even some of the most commonly used intravenous agents have poor blood-brain barrier penetrance.

\section{Staphylococcus Species}

S. aureus and coagulase-negative Staphylococcus similarly are most commonly seen in patients with recent CNS instrumentation, and as such, empiric therapy in nosocomial meningitis involving neurosurgical patients should include vancomycin in addition to the above agents while methicillin sensitivity testing is pending..$^{13}$ The addition of intraventricular vancomycin to systemic antibiotics can be considered in selected patients. ${ }^{35}$ 
Table 2 Nonbacterial meningitis and encephalitis

\begin{tabular}{|c|c|c|}
\hline Organism & $\begin{array}{l}\text { Clinical } \\
\text { considerations }\end{array}$ & $\begin{array}{l}\text { First-line } \\
\text { treatment }\end{array}$ \\
\hline \multicolumn{3}{|l|}{ Viruses } \\
\hline Herpes simplex & $\begin{array}{l}\text { Lymphocytic } \\
\text { cerebrospinal fluid } \\
\text { (CSF) pleocytosis } \\
\text { with red cells } \\
\text { present }\end{array}$ & Acyclovir \\
\hline Cytomegalovirus & $\begin{array}{l}\text { Immunocompro- } \\
\text { mised patients }\end{array}$ & Ganciclovir \\
\hline \multicolumn{3}{|l|}{ Fungi } \\
\hline Cryptococcus & $\begin{array}{l}\text { Common in immu- } \\
\text { nocompromised } \\
\text { patients }\end{array}$ & $\begin{array}{l}\text { Amphotericin B } \\
\text { and flucytosine }\end{array}$ \\
\hline Candida & $\begin{array}{l}\text { Can cause } \\
\text { endophthalmitis }\end{array}$ & $\begin{array}{l}\text { Amphotericin B } \\
\text { and flucytosine }\end{array}$ \\
\hline \multicolumn{3}{|l|}{ Protozoa } \\
\hline Toxoplasma & $\begin{array}{l}\text { Immunosup- } \\
\text { pressed patients }\end{array}$ & $\begin{array}{l}\text { Sulfadiazine and } \\
\text { pyrimethamine }\end{array}$ \\
\hline $\begin{array}{l}\text { Autoimmune } \\
\text { encephalitis }\end{array}$ & $\begin{array}{l}\text { Can have psychiat- } \\
\text { ric prodromi }\end{array}$ & $\begin{array}{l}\text { Corticosteroids or } \\
\text { immunoglobulin }\end{array}$ \\
\hline
\end{tabular}

\section{Other Bacterial Causes}

E. coli and Streptococcus agalactiae (group B strep) are common causes of neonatal meningitis, but are rarely seen in immunocompetent adults. ${ }^{6}$ Age-appropriate empiric antibiotics will provide sufficient coverage for these bacteria.

\section{Viral Meningitis and Encephalitis}

Viral meningitis, commonly referred to as aseptic meningitis, presents similarly to early bacterial meningitis, though often with a more delayed onset and self-limiting course. Patients with viral encephalitis generally present with more pronounced cognitive deficits, compared with those with bacterial meningitis, but they usually lack nuchal rigidity. As few effective antiviral treatment options exist, despite the large number of neurotrophic viruses, initial treatment should not only cover the few viruses for which treatments are available but also provide age-appropriate empiric bacterial coverage until a bacterial cause has been ruled out. ${ }^{3}$ - Table 2 provides an overview of common nonbacterial causes of meningitis and encephalitis as well as empiric treatment approaches. CSF studies in viral encephalitis often show a lymphocytic pleocytosis, usually with lower white cell count than seen in bacterial meningitis, high protein, with normal glucose, and opening pressure. ${ }^{3}$

\section{Herpes Simplex Virus}

The most widely recognized cause of viral encephalitis is herpes simplex virus (HSV), which is also one of the few treatable causes. HSV encephalitis often presents with a viral prodrome of upper respiratory symptoms, headache, and fever that progress to altered level of consciousness or psychosis, seizures, and sometimes focal neurologic findings. ${ }^{36}$ Studies have shown that early treatment with acyclovir reduces morbidity and mortality. ${ }^{37}$ Despite this, one study from 2002 showed that even in patients treated with acyclovir, $15 \%$ died and $20 \%$ had poor neurological outcome, whereas $65 \%$ had a good outcome when reassessed 6 months later. ${ }^{38}$ It is thus widely accepted that patients with a clinical picture suggestive of viral meningitis or `are started on empiric acyclovir ( $10 \mathrm{mg} / \mathrm{kg}$ every 8 hours), until HSV is excluded, or continued for 14 to 21 days if HSV is confirmed or remains highly suspected. ${ }^{1} \mathrm{~A}$ diagnosis of HSV meningitis or encephalitis can rapidly be established using PCR to detect presence of the HSV genome in the CSF. Additionally, HSV is more often associated with focal electroencephalogram (EEG) abnormalities compared with other viral encephalitides and may demonstrate characteristic MRI (magnetic resonance imaging) findings of confluent T2 hyperintensities preferentially affecting the temporal lobe. ${ }^{1}$

\section{Cytomegalovirus}

Cytomegalovirus (CMV) can cause an encephalitis presentation that is indistinguishable from other viral forms, as well as a more distinct ventriculoencephalitis that can be accompanied by radicular symptoms and cranial neuropathies. ${ }^{39}$ Immunocompromised patients are at highest risk of CMV infections of the CNS. While those with intact immunity may also be affected, they usually have a better prognosis. ${ }^{39} \mathrm{CMV}$ infections of the CNS can be treated with ganciclovir ( $5 \mathrm{mg} / \mathrm{kg}$ IV every 12 hours) or foscarnet (90 mg/kg IV every 12 hours) for a period of 14 to 21 days, continued as daily dosed maintenance therapy (for either medication). ${ }^{39}$ For patients with disease progression or recurrent disease, a combination of both medications with the same dosing protocol can be considered. ${ }^{39}$

\section{Human Immunodeficiency Virus}

While a discussion of the management of HIV infection and antiretroviral therapy choices are beyond the scope of this article, it is worth noting that HIV can cause a spectrum of neurologic disease ranging from acute aseptic meningitis, to myelitis, to dementia. ${ }^{40}$ Aseptic meningitis can be a manifestation of acute HIV infection, occurring before seroconversion (when diagnosis must be made with serum viral load rather than rapid antibody testing). ${ }^{40}$ It is important for the treating physician to identify at-risk individuals and initiate appropriate testing so that antiretroviral therapy can be started as soon as possible. While the initial aseptic meningitis caused by HIV infection is usually self-limited, later neurologic complications such as HIV-associated neurocognitive disorder may be mitigated by early and adequate antiretroviral coverage. ${ }^{41}$

\section{Meningitis Caused by Fungi and Protozoa}

Fungal meningitis is rare in immunocompetent patients. Cryptococcus is responsible for most fungal infections, followed by Coccidioides, Candida, and Histoplasma. ${ }^{42}$ Diagnosis is difficult, as most fungi grow very slowly in culture. 
CSF serology for fungal antigens or antibodies should be sent when clinical suspicion is high. Treatment of fungal meningitis is challenging, especially in resource-limited settings. Most fungi can be treated with 2 weeks of amphotericin $\mathrm{B}$ induction plus flucytosine. ${ }^{42}$

\section{Cryptococcus}

Cryptococcus neoformans and Cryptococcus gattii are two common causes of meningitis in immunocompromised patients though $C$. gattii may also affect those with intact immunity. ${ }^{3}$ Cryptococcal meningitis is increasingly common in regions that have high prevalence of HIV infection. Adults are treated with a 2-week induction course of flucytosine (25 mg/kg four times daily) and liposomal amphotericin B (3-4 mg/ $\mathrm{kg} /$ day) or lipid-complex amphotericin B ( $5 \mathrm{mg} / \mathrm{kg} /$ day IV) for 2 to 6 weeks, followed by oral flucona zole 400 to $800 \mathrm{mg} /$ day for at least 8 weeks and then $200 \mathrm{mg} /$ day for 6 to 12 months. ${ }^{44}$ Amphotericin B induction can be shortened to a 1 -week course, or replaced with fluconazole in resource-poor environments. ${ }^{42}$

\section{Candida}

Multiple species of Candida, a ubiquitous fungus, are capable of causing a classic meningitis picture, typically in immunocompromised adults. ${ }^{3}$ As endophthalmitis can complicate disseminated candidiasis, patients at risk should have a detailed ophthalmologic exam. ${ }^{3}$ Candida CNS infections are treated with an initial combination of liposomal amphotericin B (5 mg/kg/day) with or without flucytosine $(25 \mathrm{mg} / \mathrm{kg}$

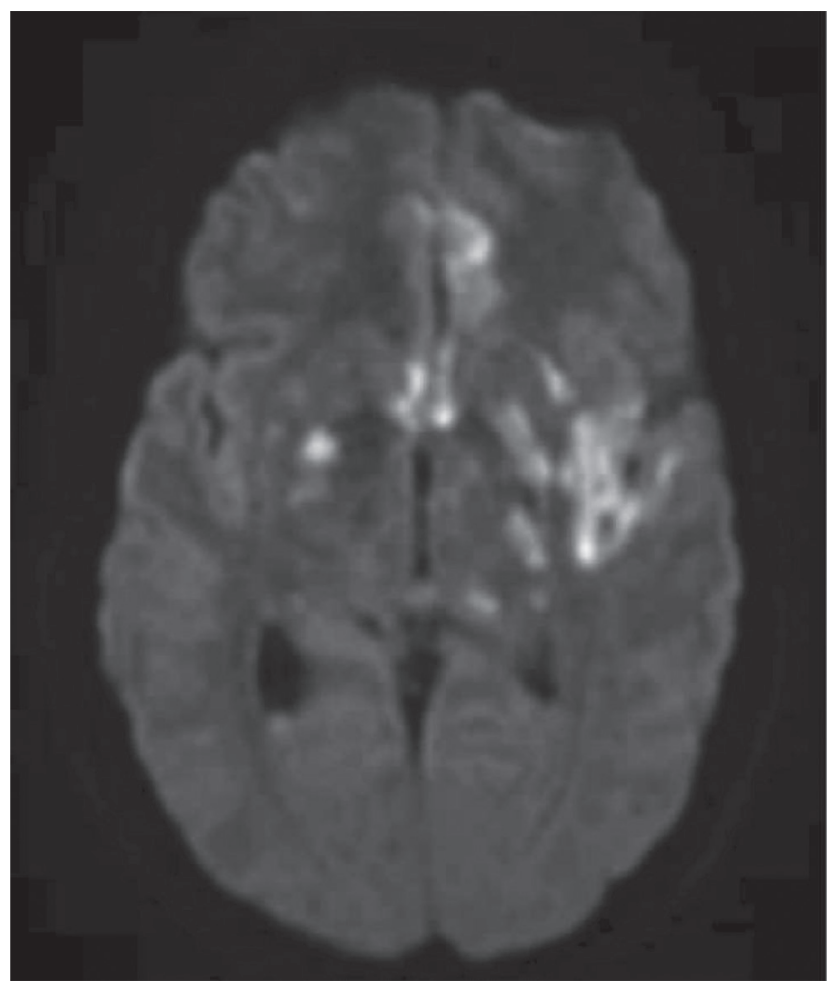

Fig. 2 Diffusion-weighted magnetic resonance imaging showing cerebral vasculitis with resulting areas of ischemia due to infection with Coccidioides immitis. four times daily) for several weeks depending on response to treatment, followed by oral fluconazole $(6-12 \mathrm{mg} / \mathrm{kg} / \mathrm{day})$ until CSF and imaging studies have normalized. ${ }^{44}$

\section{Coccidioides}

Coccidioides immitis and C. posadasii are species of dimorphic fungi that are prevalent in the southwestern United States and Mexico. ${ }^{44}$ CNS involvement can present as a meningoencephalitis, though hydrocephalus and vasculitis that can cause stroke ( $\mathbf{- F i g}$. 2) are common complicating manifestations. ${ }^{44}$ Long-term oral fluconazole $(400-1,200 \mathrm{mg} /$ day) is the initial treatment of choice, with higher doses for those who fail initial therapy or with more severe presentations. ${ }^{44}$ Treatment is often lifelong. Intrathecal amphotericin $\mathrm{B}$ can be considered in the gravely ill and in pregnancy. ${ }^{44}$

\section{Mold}

CNS infections caused by mold (e.g., Aspergillus, Mucorales, Fusarium species) are exceedingly rare. They occur in severely immunocompromised patients or as a consequence of iatrogenic contamination. Amphotericin B and voriconazole are mainstays of therapy for mold infections. ${ }^{45}$

\section{Toxoplasma gondii}

Toxoplasma gondii is an intracellular protozoan parasite capable of causing systemic illness as well as meningoencephalitis, most commonly in those with impaired immunity. ${ }^{46}$ The initial treatment regimen consists of sulfadiazine (1,000-1,500 $\mathrm{mg}$ four times daily) and pyrimethamine (200 mg loading followed by $50-75 \mathrm{mg}$ daily) and leucovorin to protect against pyrimethamine-related toxicity ${ }^{46}$ Clindamycin (600 mg four times daily) is an alternative regimen for those with allergies to sulfa drugs. ${ }^{46}$ Trimethoprimsulfamethoxazole can be considered as an alternative when resources are scarce or if intravenous formulations are preferred. ${ }^{46}$

\section{Noninfectious Encephalitis}

\section{Autoimmune Encephalitis}

Significant progress in the identification of autoantibodies over the past two decades has increased recognition of autoimmune and paraneoplastic encephalitides as distinct noninfectious entities. The syndromes vary but typically include a constellation of symptoms such as psychosis, encephalopathy, seizures, and movement disorders ${ }^{47}$ that can mimic viral encephalitides clinically, radiographically, and on initial diagnostic testing, including lymphocytic pleocytosis ${ }^{48}$ High-dose corticosteroids, plasma exchange, and intravenous immunoglobulins are each accepted as first-line empiric treatments, though choosing which to initiate and when is case- and practitioner-dependent. ${ }^{48}$ As confirmatory testing is still confined to specialized laboratories and reporting is frequently delayed by several days, it remains an unresolved question when in the clinical course empiric immunomodulatory treatment should be initiated. 


\section{Conclusion}

Meningitis and encephalitis are two clinical syndromes that can have a variety of presentations and often require astute considerations when determining their etiology. Failure to adequately treat a patient with acute inflammation of the CNS carries a high risk of increased morbidity and mortality. It is thus paramount that practitioners be familiar not only with the clinical characteristics of these diseases but also with the most effective early interventions. Empiric treatments have been firmly established for many of the most commonly encountered pathogens. Rising antibiotic resistance patterns must be considered when determining a patient's full treatment course, and underscore the importance of isolating and identifying the organism. Autoimmune conditions should remain as a differential diagnosis, especially in instances of clinical encephalitis without a clear cause.

\section{Disclosures}

The authors have no financial disclosures.

\section{Conflict of Interest}

None declared.

\section{References}

1 Tyler KL. Acute viral encephalitis. N Engl J Med 2018;379(6): 557-566

2 Costerus JM, Brouwer MC, Bijlsma MW, van de Beek D. Community-acquired bacterial meningitis. Curr Opin Infect Dis 2017;30(1):135-141

3 Giovane RA, Lavender PD. Central nervous system infections. Prim Care 2018;45(3):505-518

4 Tunkel AR, Hasbun R, Bhimraj A, et al. 2017 Infectious Diseases Society of America's Clinical Practice Guidelines for Healthcare-Associated Ventriculitis and Meningitis. Clin Infect Dis 2017. doi: 10.1093/cid/ciw861

5 Auburtin M, Wolff M, Charpentier J, et al. Detrimental role of delayed antibiotic administration and penicillin-nonsusceptible strains in adult intensive care unit patients with pneumococcal meningitis: the PNEUMOREA prospective multicenter study. Crit Care Med 2006;34(11):2758-2765

6 van Ettekoven CN, van de Beek D, Brouwer MC. Update on community-acquired bacterial meningitis: guidance and challenges. Clin Microbiol Infect 2017;23(9):601-606

7 Khatib U, van de Beek D, Lees JA, Brouwer MC. Adults with suspected central nervous system infection: a prospective study of diagnostic accuracy. J Infect 2017;74(1):1-9

8 Sanaei D A, Alizadeh S, Karimi A, Khalifeh M, Shoja SA. Diagnostic value of lactate, procalcitonin, ferritin, serum-C-reactive protein, and other biomarkers in bacterial and viral meningitis: a cross-sectional study. Medicine (Baltimore) 2017;96(35):e7637

9 Vikse J, Henry BM, Roy J, Ramakrishnan PK, Tomaszewski KA, Walocha JA. The role of serum procalcitonin in the diagnosis of bacterial meningitis in adults: a systematic review and meta-analysis. Int J Infect Dis 2015;38:68-76

10 Viallon A, Botelho-Nevers E, Zeni F. Clinical decision rules for acute bacterial meningitis: current insights. Open Access Emerg Med 2016;8:7-16

11 McGill F, Heyderman RS, Panagiotou S, Tunkel AR, Solomon T. Acute bacterial meningitis in adults. Lancet 2016;38810063: 3036-3047
12 McIntyre PB, O’Brien KL, Greenwood B, van de Beek D. Effect of vaccines on bacterial meningitis worldwide. Lancet 2012;3809854:1703-1711

13 van de Beek D, Brouwer MC, Thwaites GE, Tunkel AR. Advances in treatment of bacterial meningitis. Lancet 2012;3809854: 1693-1702

14 Verghese VP, Veeraraghavan B, Jayaraman R, et al. Increasing incidence of penicillin- and cefotaxime-resistant. Streptococcus pneumoniae. causing meningitis in India: time for revision of treatment guidelines? Indian J Med Microbiol 2017;35(2): 228-236

15 Thigpen MC, Whitney CG, Messonnier NE, et al; Emerging Infections Programs Network. Bacterial meningitis in the United States, 1998-2007. N Engl J Med 2011;364(21):2016-2025

16 van de Beek D, de Gans J, Tunkel AR, Wijdicks EF. Community-acquired bacterial meningitis in adults. $\mathrm{N}$ Engl J Med 2006;354(1):44-53

17 Green C, Moore CA, Mahajan A, Bajaj K. A simple approach to pneumococcal vaccination in adults. J Glob Infect Dis 2018;10(3):159-162

18 Tunkel AR, Hartman BJ, Kaplan SL, et al. Practice guidelines for the management of bacterial meningitis. Clin Infect Dis 2004;39(9):1267-1284

19 Brouwer MC, McIntyre P, Prasad K, van de Beek D. Corticosteroids for acute bacterial meningitis. Cochrane Database Syst Rev 2015;(9):CD004405

20 Cottagnoud P, Täuber MG. Fluoroquinolones in the treatment of meningitis. Curr Infect Dis Rep 2003;5(4):329-336

21 Kanellakopoulou K, Pagoulatou A, Stroumpoulis K, et al. Pharmacokinetics of moxifloxacin in non-inflamed cerebrospinal fluid of humans: implication for a bactericidal effect. J Antimicrob Chemother 2008;61(6):1328-1331

22 Heckenberg SG, de Gans J, Brouwer MC, et al. Clinical features, outcome, and meningococcal genotype in 258 adults with meningococcal meningitis: a prospective cohort study. Medicine (Baltimore) 2008;87(4):185-192

23 Nathan N, Borel T, Djibo A, et al. Ceftriaxone as effective as long-acting chloramphenicol in short-course treatment of meningococcal meningitis during epidemics: a randomised non-inferiority study. Lancet 2005;3669482:308-313

24 Mylonakis E, Hohmann EL, Calderwood SB. Central nervous system infection with. Listeria monocytogenes. . 33 year's experience at a general hospital and review of 776 episodes from the literature. Medicine (Baltimore) 1998;77(5):313-336

25 van de Beek D, de Gans J, Spanjaard L, Weisfelt M, Reitsma JB, Vermeulen M. Clinical features and prognostic factors in adults with bacterial meningitis. N Engl J Med 2004;351(18):1849-1859

26 Zunt JR. Tuberculosis of the central nervous system. Continuum (Minneap Minn) 2018;24(5, Neuroinfectious Disease):1422-1438

27 World Health Organization. Guidelines for Treatment of DrugSusceptible Tuberculosis and Patient Care. Published 2017 (2017 Update). Available at: https://www.who.int/tb/publications/ 2017/dstb_guidance_2017/en/. Accessed December 18, 2018

28 Iseman MD. Treatment of multidrug-resistant tuberculosis. N Engl J Med 1993;329(11):784-791

29 Garg RK, Rizvi I, Malhotra HS, Uniyal R, Kumar N. Management of complex tuberculosis cases: a focus on drug-resistant tuberculous meningitis. Expert Rev Anti Infect Ther 2018;16(11):813-831

30 Halperin JJ. Neuroborreliosis and neurosyphilis. Continuum (Minneap Minn) 2018;24(5, Neuroinfectious Disease:1439-1458

31 Halperin JJ, Shapiro ED, Logigian E, et al; Quality Standards Subcommittee of the American Academy of Neurology. Practice parameter: treatment of nervous system Lyme disease (an evidence-based review): report of the Quality Standards Subcommittee of the American Academy of Neurology. Neurology 2007;69(1):91-102 
32 Centers for Disease Control and Prevention. Sexually Transmitted Diseases Treatment Guidelines. Published 2015. Available at:https://www.cdc.gov/std/tg2015/default. htm. Accessed December 23, 2018

33 Lewin JJ, III,. Cook AM, Gonzales C, et al. Current practices of intraventricular antibiotic therapy in the treatment of meningitis and ventriculitis: results from a multicenter retrospective cohort study. Neurocrit Care 2019;30(3):609-616

34 Mrowczynski OD, Langan ST, Rizk EB. Intra-cerebrospinal fluid antibiotics to treat central nervous system infections: a review and update. Clin Neurol Neurosurg 2018;170:140-158

35 van de Beek D, Drake JM, Tunkel AR. Nosocomial bacterial meningitis. N Engl J Med 2010;362(2):146-154

36 Steiner I, Benninger F. Manifestations of herpes virus infections in the nervous system. Neurol Clin 2018;36(4):725-738

37 McGrath N, Anderson NE, Croxson MC, Powell KF. Herpes simplex encephalitis treated with acyclovir: diagnosis and long term outcome. J Neurol Neurosurg Psychiatry 1997;63(3):321-326

38 Raschilas F, Wolff M, Delatour F, et al. Outcome of and prognostic factors for herpes simplex encephalitis in adult patients: results of a multicenter study. Clin Infect Dis 2002;35(3):254-260

39 Maschke M, Kastrup O, Diener HC. CNS manifestations of cytomegalovirus infections: diagnosis and treatment. CNS Drugs 2002;16(5):303-315

40 Saylor D. Neurologic complications of human immunodeficiency virus infection. Continuum (Minneap Minn) 2018;24(5, Neuroinfectious Disease):1397-1421
41 Heaton RK, Franklin DR, Ellis RJ, et al; CHARTER Group; HNRC Group. HIV-associated neurocognitive disorders before and during the era of combination antiretroviral therapy: differences in rates, nature, and predictors. J Neurovirol 2011; 17(1):3-16

42 Molloy SF, Kanyama C, Heyderman RS, et al; ACTA Trial Study Team. Antifungal combinations for treatment of cryptococcal meningitis in Africa. N Engl J Med. 2018;15;378(11):1004-1017

43 Gottfredsson M, Perfect JR. Fungal meningitis. Semin Neurol 2000;20(3):307-322

44 Góralska K, Blaszkowska J, Dzikowiec M. Neuroinfections caused by fungi. Infection 2018;46(4):443-459

45 McCarthy M, Rosengart A, Schuetz AN, Kontoyiannis DP, Walsh TJ. Mold infections of the central nervous system. N Engl J Med 2014;371(2):150-160

46 Panel on Opportunistic Infections in Hiv-Infected Adults and Adolescents, . Guidelines for the Prevention and Treatment of Opportunistic Infections in HIV-Infected Adults and Adolescents: Recommendations from the Centers for Disease Control and Prevention, the National Institutes of Health, and the HIV Medicine Association of the Infectious Diseases Society of America. Published2018. Available at:http:// aidsinfo.nih.gov/contentfiles/lvguidelines/adult_oi.pdf. Accessed January 1, 2019

47 Al-Diwani A, Handel A, Townsend L, et al. The psychopathology of NMDAR-antibody encephalitis in adults: a systematic review and phenotypic analysis of individual patient data. Lancet Psychiatry 2019;6(3):235-246

48 Hermetter C, Fazekas F, Hochmeister S. Systematic review: syndromes, early diagnosis, and treatment in autoimmune encephalitis. Front Neurol 2018;9:706 